\title{
The Paradoxical Effects of Uncertainty: A perspective of South Africa's Risk Adjusted Strategy on COVID-19
}

Jeremiah Kau Makokoane

The Southern Africa Institute of Management Scientists, Independent researcher, South

Africa

\begin{abstract}
The emergence of the coronavirus SARS-CoV-2 which causes the COVID-19 disease was on 11 March 2020 declared a public health pandemic by the World Health Organization since it threatens human life and livelihood. Covid-19 which originates from China has stretched across nations globally from the end of 2019. In administering public policy of affected countries each government has adopted a counter strategy of containing this biological outbreak. The consequential effects are restricted movements on socio-economic activities. Thus, this paper provides theory development of a cross-disciplinary study drawing upon insights from literature on uncertainty and disaster risk management that is integrated with system theory, adaptive systems and practices as well as decision-making philosophy. That provides a basis for exploration of international perspectives on disaster risk reduction methods to combat the Covid-19 pandemic. Following, this paper explains the formulation of the South Africa's Risk Adjusted Strategy. The collected scientific data and associated information enable risk analysis experts and key stakeholders to empower political decisionmaking in strategy execution. The anticipated strategic interventions are to alleviate a debilitating socio-economic situation by public policy and adaptation strategies towards a return to socio-economic normalcy. However, the potential paradoxical effects of COVID-19 are expected to create an ambivalent attitude to strategic interventions and decision-making by authorities. Thus, this paper seeks to explore the theoretical and practical ramifications of the systemic change and adaptable disaster risk strategy of South Africa within the context of disaster risk management and under extraordinary situations of uncertainty during the COVID-19 pandemic.
\end{abstract}

Keywords: Covid-19 effects of uncertainty, Disaster risk management, South Africa's Risk Adjusted Strategy, Paradox of Covid-19

\section{Introduction}

COVID-19 poses uncertainty to socio-economic sustenance of nations, globally. Consequently, it creates pressing situations that invoke counter response through the use and formulation of appropriate policies and strategies by decision-makers. Therefore, this paper seeks to provide insight regarding the COVID-19 effects of uncertainty and the subsequent response to the health hazard by South African government. The paper is not an attempt to search for epidemiological interventions but it examines the relevance of risk management under conditions of severe uncertainty. South Africa's government has decided to heighten regulatory measures and contemplate alternative mitigating options against unpredictable COVID-19 outcomes to contain and reduce possible socio-economic negative impacts. The assumption is that by virtue of their adopted framework termed South Africa's Risk Adjusted Strategy (RAS) decision-makers will proactively determine prognosis of uncertainty reduction elements against the predicted occurrence of undesirable COVID-19 outcomes. Also, that it might become easier to provide clarity of explanation to any deviation from the forecasted range of data of the COVID-19 
outcome level which informs the varying projected scenarios of the COVID-19 phenomenon. Accordingly, as a result in uncertainty reduction the expected public value outputs should make sense of the peculiarity situation of the COVID-19 event.

However, the inadequacy of information exacerbates the status of the reliability from aspects of the COVID-19 phenomenon which bear multiplicity of probable causes and associated effects. The interpretive cues of possible results from collected data with objective scientific evidence encourage a possible resolve in the long run. Moreover, scenario planning is critical in guiding scientific reasoning process and political decision-making on the uncertainty situation. Despite, the prevailing indeterminacy of causal effects and appropriate remedy from COVID-19 are complex and requires comprehensive analysis of the phenomenon itself. Therefore, this paper posits that South Africa in following its risk management process has sought to assess the Covid19 risk factors by stakeholder inputs and feedback before taking discreet judgement by authorities. A defined Covid-19 alert system of delineated levels of permissions and restrictions is imposed by the authorities along adapted epidemiological trends. In turn, the attained residual risk outcomes of the Covid-19 event at a particular time are deemed acceptable or intolerable with authorities reviewing the prevailing situation before altering or prolonging Covid-19 restrictions. Thus, conceptualizing of Covid-19 risk profile emphasises prioritisation of Covid-19 disease control measures by policy and regulatory response. The suggested choice of risk strategies are uncertainty interventions through the RAS. The strategies cover The Precautionary Principle Approach, The Lead Agency Model to Communication Strategy, COVID19 Data and Modelling Strategy, COVID-19 Uncertainty and Decision-Making, as well as The paradox of Covid-19 expenditure against the national development strategy. The execution of these strategies seeks to balance sustenance of economic activities while protecting loss of live under arduous Covid-19 situation. Therefore, the focus of this paper is to a great extent interchangeably on both the social and economic contradictions brought about by the COVID19 pandemic. It further presents how the different responses to the situation intersect and contrast with each other. In considering the various kinds of "contrasts", noting the action of South African government to the ambiguous COVID-19 event, the reduction of a social strain is in a regrettable order conflicting with the economic aspirations for the country.

This paper at first focuses on the development of theory as a precursor to the description and proposed paradoxical effects of COVID-19 pandemic on South Africa's people and the economy.

\section{Theoretical Framework}

\subsection{Uncertainty}

In general, researchers and management literature explain uncertainty as the inability to predict the effect of or response to the probable outcomes of an occurrence (Chintakananda1 et al., 2015). The nature, level and location of uncertainty is deemed to display the context of its existence (Kreye et al, 2011; Walker et al., 2003). Economists propose that the multidimensional nature of uncertainty exists in three types, namely, probability, ambiguity and complexity. Probability uncertainty is suggested to exist when probability is unknown or misunderstood while creating difficult situations to work out risk levels. Ambiguity uncertainty is found in conditions where information generate conflicting views, either vague or inadequate. Complexity uncertainty happen under a situation that is technically complex and causing difficulties to understand or solve a complex issue (Dequench, 2011; Menon \& Kyung, 2020). Notwithstanding the description, Kreye et al. (2011) hypothesizes that uncertainty can manifests in the form of input information, through the model structure, or by observation of the outcome of a phenomenon. The nature and relationship of uncertainty types are depicted in Figure 1 below. Information (data) uncertainty (Figure 1) is about poor or lack of information which is necessary to improve insight into the information used to analyse a situation. In collecting information or data to improve decision-making about an issue, uncertainty and the level of inexactness are reduced while the meaning of a particular event is made clear. However, the level of uncertainty is distinguished as substantive uncertainty on the basis of sufficient or 
lack of good-quality information necessary for analysis and informed decision-making (Thomson et.al, 2005; Dequench, 2011).

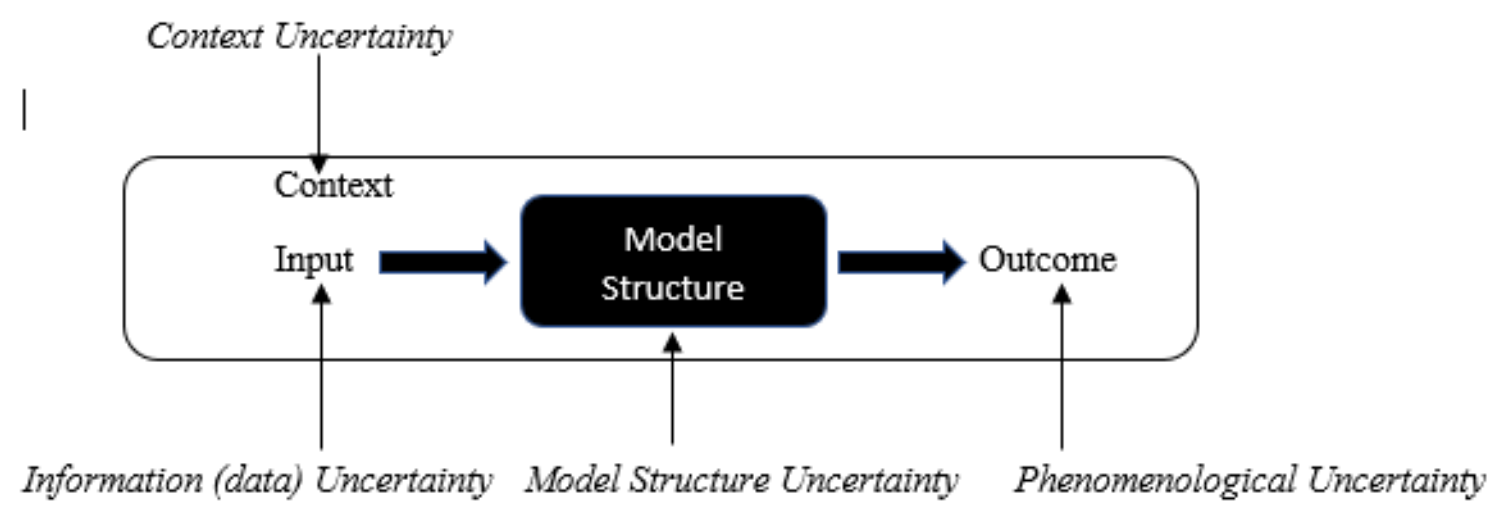

Figure 1: Manifestation of Uncertainty (Adapted from Kreye et al, 2011)

In that regard the application of a data reduction equation by a scientific model and reasoning process unveils conspicuous predictions of variables by multiple determinations while explaining the intricacies of an occurrence. Therefore, complex inference problems use data as a basis for testable propositions and probabilities of alternative outcomes over the hypothesis in the model structure uncertainty (Walker et al., 2003; Redmond, 2015). However, outcomes of a process that involves a scenario planning exercise are dictated by purpose and attention to the imperatives for change (Lindgren \& Bandhold, 2003, p. 48). The Laplace Rule (1812) also called the Principle of Insufficient Reasoning, argues that although all conceived scenarios are deemed as equally likely, it is best to choose a strategy with the optimal outcome in a situation. This notion is complemented by Wald's Maximin Principle (1945) which asserts that the optimal decision chosen under uncertainty should be of a scenario of strategies of the possible least bad outcome. Notwithstanding, the application of scenario planning through technical reasoning is insufficient under conditions of severe uncertainty (Gurkov, 2010). And, knowing the available options does not diminish the existence of ambiguity of the unreliable probable outcome of each alternative predetermined event (Dequech, 2011). Moreover, the knowledge of alternative measurements of uncertainty can also be extracted by logic of belief and idealized model of the world situation (Walker et al., 2003).

\subsection{Uncertainty, Systems Theory and Adaptive Practices}

Three types of organizational change models which constitute the complex adaptive systems construct are systems theory, information processing and organizational learning (Dooley, 1997). Systems thinking is concerned with complexity of the system wide phenomenon which is featured with interconnection of activities and their changing effect on the system (Simonovic, 2015). In changing a small amount of the system, the behavioural outcome from the change can have far-reaching consequences on the whole system (Anderson, 1999). Moreover, the dynamic behaviours of the system activities that borders on a chaotic situation generate a complex whole filled with paradoxical effects (Dooley,1997). Hence, systems theory recognizes the dynamics of multiple cause-and-effect relationship which arises from intertwined and indiscriminate activities. That includes major natural disasters which are associated with situations of surmountable danger to human life and property (Simonovic, 2015). As a result, organizational agents of change continue to pursue emergence of order against unpredictable outcomes which are caused by impact on the complex adaptive systems (Byrne 1998; Burnes, 2005). Meanwhile the connected components of complex systems create a web of feedback loops by changing inputs to non-linear outputs which brings a new order to the environmental cues (Anderson,1999). Subsequently, as a reflective process, individuals are able to enquire extensively into the causes of the problematic issue. In turn new ways and different undertakings are embarked on and thus introducing a paradigm shift of behavioural adaption to the environment (Tosey et al., 2012; Ramalingam et al., 2020). Ramalingam et al. (2020) posit 
that an adaptive management approach will seek to identify appropriate interventions by understanding the reasons, methods and impacts of interventions to a social order. Hence, strategies are planned to adjust to change by policy-makers, researchers and practitioners (Ibid).

Management capability related to a disaster response involves preparedness in planning, both in training and management of a hazardous situation, and the identification and analysis of vulnerabilities and risks (Mileti, 1999). Therefore, in ensuring that order is re-established the planning is founded on a process that incorporates control measures and predictability (Gorod et al., 2018; Simonovic, 2015). Also, multiple stakeholders involved are likely to develop techniques for acceptable hazard assessment processes by information sharing and knowledge transfer to formulate mutual aid agreements (Quarantelli, 1998). The probability, impact and intensity of the hazard, given the anticipated exposure to political-, social-, physical- and / or economic- vulnerability with consideration of available resources and capacity to manage the hazards is established as a disaster risk. Therefore, the United Nations Office for Disaster Risk Reduction (UNISDR)'s mathematical definition of Risk = Hazard $\mathrm{x}$ Exposure $\mathrm{x}$ Vulnerability (https://www.preventionweb.net). Alternatively, some researchers consider risk as inversely proportional to capacity or resilience as denoted by: Risk a 1/capacity (Mamuji \& Edkin, 2019). Hence, the mathematical expression of a Disaster Risk can be defined as:

$$
\text { Disaster risk }=\frac{\text { Hazard } \mathrm{x} \text { Exposure } \mathrm{x} \text { Vulnerability }}{\text { Capacity }}
$$

Along these lines, The Sendai Framework for Disaster Risk Reduction 2015-2030 (The Sendai Framework) by the United Nations (UN) endorsed the requirement of "a multi-hazard approach and inclusive risk-informed decision-making based on the open exchange and dissemination of disaggregated data" as one of the thirteen guiding principles for a strategy on disaster risk reduction for member countries (UNISDR, 2015, p. 13).

\subsection{Decision Making under Uncertainty}

The Precautionary Principle serves as a guiding tool of decision-making under situations of uncertainty and possible large-scale catastrophic outcomes. The principle is critical to depoliticise the uncertainty phenomenon of regulatory inaction likely to inflict irreversible harm by crippling the environmental management process (Funtowicz \& Ravets, 1990). In this regard, in conceptualising this principle, though not universally acceptable, Gee and Krayer von Krausss (2005) established that the principle justify intervention by public policy when the exigencies of harm to the health or the environment are under conditions of scientific complexity, uncertainty and ignorance. They further argue that scientific evidence that is suitable to the problematic situation should be used with due consideration of both the likely positive and negative effects of action and inaction. On the other hand, normative literature provides varying approaches to strategic decision making while the related narrative exposition of stages to finding a solution unveils the convergence of ideas by analytical methods. Mintzberg, Raisinghani, and Théorêt (1976) summarize how Hebert Simon (1960) compressed John Dewey's (1910)'s five stage problem-solving technique to three parts process of decision making successively from the first termed intelligence, followed by design and thirdly to choose. Although Mintzberg et al., (1976) kept to Simon's three phase approach towards decision making, they differently labelled each phase. Simon's "intelligence" stage is made intelligible through two successive procedures jointly termed the identification phase. First, through the decisions recognition procedure "opportunities, problems and crises" are identified and acted upon (Mintzberg et al.1976, p. 252-253). Secondly, the diagnosis course paves a way of clarifying the prevailing ambiguity by information gathering and determination of complex causal nexus of the problematic situation. Simon's "design" stage is titled the "development phase" that is comprised of two sub-phases, that is, the search subpart and design subpart. The search routine is for exploring alternative ready-made solutions for adoption, while the design procedure seeks customized and selfproduced solutions. The "choice" phase of Simon's (1960) is translated to the selection phase 
that is comprised of three sequential paths. In the first path called the screen routine the readymade searched solutions are sifted in order to dispose relatively poor solutions from the best options. In turn, the second path called the evaluation-choice routine explains the required judgement, bargaining process and analysis. From screening of options, the remaining possibilities are assessed by discrete judgement of individuals. The succeeding bargaining process uncover contentious goal choices of group members which are consequently contemplated by cohort decision makers. In general, the fact-finding technique by experts provides a basis for analysis that is beneficial for managerial judgement or bargaining. Eventually, authorization obtained from the final hierarchy serves as a seal of an approval for the solution.

From all of the three routines, Mintzberg et al.'s (1976) study suggests that the routine judgement befits data that is grounded in strategic decision making. Also, that the judgement route is much preferred since it involves least arduous efforts to make timely decisions. Alternatively, the bargaining route to decision making process becomes unavoidable when multiple stakeholder participation or external control of debatable issues are fundamental to problem-solving of the event (Ibid). In view of these considerations, Mintzberg et al. (1976) departed from a sequential proposition of decision-making process to a non-sequential method on the basis that decision-making processes are circular in nature rather than linear. In that, decision-makers are likely to cycle within search, design and evaluation activities to cycling between selection and development routes before a final judgement is arrived at. Therefore, the selection of strategic alternative decisions that requires thoughtful and reflective thinking is made complex when factors are dynamic and featured with uncertainty (Ibid). Nevertheless, decision theory suggests that a risk happen under conditions of known probabilities. At the same time decision-makers are striving for rationality in decision-making within the boundary of available information limited by their social system. Moreover, decision-makers strive to attain sustainable and resilient disaster risk management (DRM) by adjusting policies. They also integrate political and technological processes along systems of society to contain risks (Mileti, 1999; Simonovic, 2015). Thus, it is presumed that the state of complexity and context-specific objectives dictate decision-making which is informed by the prospect of an event to happen.

\subsection{Disaster Risk Management under Uncertainty}

Van de Kuilen and Wakker (2006) in support of Tversky and Kahneman (1992) posit that the decision rule of prospect theory is likely to favour a safe disposition over a risky situation when decision makers put too much weight on severe outcomes proportional to modest outcomes. This implies that the notion of risk is concerned with negative impacts and thus a high-risk decision may be linked with potential catastrophic consequences. Bekkers and Thaens (2005) argue that the theory of risk is convoluted by the modern societal life which compels governments and private organizations to use risk governance models as tools to compensate policy-making. The governance strategies are presumed to simplify risk management in preserving the value of humans while also expediting the prediction of unwanted events. The numerous methods of grouping adaptive strategies of DRM can either be in logical clusters or themes by an iterative and evaluation process. The exposition thereof when appraised sooner and within defined timelines is likely to assist in examining the problematic uncertainty and how to prevent it happening (Nojavan et al., 2018). Accordingly, DRM is regarded as an effective strategy concerning a response to disaster prevention or an attempt to recover from a disastrous phenomenon. Simonovic $(2015$, p.73) suggests that

\footnotetext{
"Integrated disaster management is an iterative process of decision-making regarding prevention of, response to, and recovery from a disaster."
}

Hence the established construct of DRM follows four stages from prevention, mitigation, response and up to recovery from a disaster (Simonovic 2015; Nojavan et.al., 2018). In stating six sustainable principles that ameliorate the dire effects of natural disasters Denis Mileti (1999, p. 30 - 34) suggests that the human quality of life and the environment quality are important 
and thus need to be preserved. That can be made possible when local economies are viewed as indispensable and local resiliency in response to a disaster is cultivated. The dynamic participatory process of consensus-building is also crucial when initiated from the local level to set a foundation for mitigating against a disaster situation (Mileti, 1999). Also, it is vital to balance timeous actions that support robust policies as essential efforts to protect loss of life, damage to property while avoiding environmental degradation in general. Such immediate response when effectively engaged may reshape and redirect the effects of a catastrophe. It is thus important to cover the whole region affected by a disaster in order to mitigate against the grant total of the hazard while also restoring a locality's social standard of quality (Mileti, 1999; Simonovic 2015). Activities meant to restore a social order and recovery of important support systems from a disaster are realised through disaster relief programs and spontaneous volunteerism amongst members of a society (Mileti, 1999). In turn a range of plausible futures would require the positioning and availability of both material, financial and interdisciplinary human resources (Quarantelli,1998; Simonovic, 2015). Subsequently, an integrative systemic approach may enable the achievement of a holistic solution to a complex and uncertain situation of DRM. Accordingly, this paper examines the development and implementation effects of the South Africa's adaptable disaster risk strategy within the context of DRM and under extraordinary situations of uncertainty of the COVID-19 pandemic. Firstly, an international experience of DRM of influenza pandemics is given.

\section{An International Perspective of Influenza Pandemics}

The UN asserts that the amplitude nature of a pandemic is pervasive worldwide with outbreaks of disastrous epidemic proportions that tends to debilitate national economies, the local social fabric, and disintegrate political systems (https://www.un.org/). Thus, the forerunner influenza pandemics of the COVID-19 include the Spanish Flu (1918/19) with at least 50 million mortalities, the Asian flu (1957) pandemic reached about 2 million fatal cases, and the Swine Flu (1957) resulted in death levels of half a million (UK Government, 2020). The arrival of COVID-19 which is distinguished as a pandemic and a disaster has elicited strategic responses by authorities of affected countries across the globe (Rodrigues et al., 2020). The Sendai Framework emphasises the need for States to understand disaster risks so as to bolster disaster risk governance while demonstrating resilience to risk reduction. That is to be made easier by adaptive strategies of disaster preparedness, effective response and immediate recovery actions (UNISDR, 2015, p.14).

The disaster risk plans of Australia, United Kingdom and Brazil give insight into strategic response by some countries to the COVID-19 pandemic. Australia's National Communicable Disease Plan (National CD Plan) of May 2018 delineate governance responsibilities about inevitable emergency response affecting the health sector. The adopted lead agency model approach enables Australia's national Department of Health to spearhead the country response in tackling the January 2020 confirmation of Covid-19 disease in Australia (IMF, 2020). In turn, cross-government committees share ancillary Covid-19 risk information to society during the pandemic (Australian Government, 2018). Notably, Australia reported a Covid-19 death level of 888 by 1 October 2020. However, it is inconclusive as to whether the low fatalities result from an effective Covid-19 response or a high-quality health care system (Patrick, 2020). Still, Australia's 3-step cautionary approach gradually allowed gatherings and business activities increasingly over time within the COVIDSafe standards (Australian Government, 2020). Differently, the COVID-19 action plan by the government of the United Kingdom is a collective responsibility of the healthcare systems of England, Scotland, Wales and Northern Ireland. Through partnership with local and regional health organizations the four Chief Medical Officers (CMOs) of the four territories collaborate in advising the UK government on suitable health disaster response techniques against the Covid-19 situation. In concert, the Scientific Advisory Group for Emergencies (SAGE) coordinate and provide scientific judgement to decision makers (UK government, 2020). Thus, it is suggested that the 
The Southern Africa Institute of Management Scientists, Independent researcher, South Africa

UK government has embraced the all-agency model strategy through SAGE so as to enhance collective expertise and broader perspectives from all various and relevant agencies in developing critical responses. The confirmed existence of Covid-19 in UK on 31 January 2020 invoked the country's three-tiered COVID-19 alert system with restrictions of gathering escalated from the medium alert level to the high alert level and the very high alert level countrywide (IMF, 2020). Rigid restrictions followed the resurgence of Covid-19 spread with cases surpassing one million in early November 2020 (Agencies and Sum, M., 2020).

Antithetically, some researchers and opinion-makers deplore the apparent ineptitude of the Brazilian State in responding to the COVID-19 pandemic. The anti-scientific stance taken by the President and the disrespect of quarantine measures by citizens is scolded for aggravating the untenable situation. Government is blamed for lip service since already by August 2020 over 100000 Covid-19 related deaths were reported (Phillips, 2020). However, the Public Health Emergency Response Plan (PRESP) to Covid-19 was activated early January 2020 and like UK it follows a three-tier level of disaster management approach. Differently, the lowest intensity of Covid-19 spread (Level 1 ) is responded to by the local sphere of government. Alternatively, the Covid-19 medium intensity (Level 2 ) is a co-responsibility of local and Federal governments. Ultimately, a high intensity (Level 3 ) is considered overwhelming and thus marshalled and coordinated by the National Civil Protection and Defense System (SINPDEC) (Rodrigues et al., 2020). Therefore, after the Federal government of Brazil has issued directives to close nonessential business activities and schools, it is presumed that SINDEC responded accordingly (WorldAware, 2020).

The exposition of the Covid-19 responses by Australia, UK and Brazil is made more intelligible by comparative research work of YouGov, WHO, Johns Hopkins and the International Monetary Fund (IMF). The comparison of the number of Covid-19 death cases per hundred thousand of the population suggests (Table 1) that in general Australia's approach to the Covid-19 has relatively shown success as against UK, Brazil and South Africa.

Table 1: Comparisons of effectiveness of response to Covid-19 pandemic by four countries

\begin{tabular}{|c|c|c|c|c|c|c|}
\hline Country & $\begin{array}{l}\text { Population } \\
\text { Total } \\
\text { (in Millions) }\end{array}$ & $\begin{array}{l}\text { Unemployment } \\
\text { total (\% of } \\
\text { total labour } \\
\text { force), } 2020\end{array}$ & $\begin{array}{l}\text { You } \\
\text { Glo } \\
\text { Unv } \\
\text { sam } \\
\text { Fond }\end{array}$ & $\begin{array}{l}\text { Survey } \\
\text { m } 2020 \\
\text { ted } \\
\text { / Dislike }\end{array}$ & $\begin{array}{l}\text { WHO } \\
\text { Cumulative } \\
\text { cases per } 1 \\
\text { million } \\
\text { population }\end{array}$ & $\begin{array}{l}\text { Johns } \\
\text { Hopkins } \\
\text { Mortality } \\
\text { Analysis } \\
\text { (Death/100k } \\
\text { population) }\end{array}$ \\
\hline Australia & 25,364 & $5.3 \%$ & $74 \%$ & $20 \%$ & 1082 & 3.63 \\
\hline UK & 66,834 & $4.1 \%$ & $39 \%$ & $54 \%$ & 14902 & 70.60 \\
\hline Brazil & 211,049 & $12.0 \%$ & $36 \%$ & $62 \%$ & 25953 & 76.50 \\
\hline $\begin{array}{l}\text { South } \\
\text { Africa }\end{array}$ & 58,558 & $28.5 \%$ & $59 \%$ & $41 \%$ & 12232 & 33.69 \\
\hline
\end{tabular}

Source: The World Bank "Population Total", 2019; The World Bank "Unemployment Total", 2020; YouGov "Cambridge Globalism", 2020; WHO https://www.who.int/, Johns Hopkins, 2020.

The YouGov's globalism survey conducted between July 2020 to August 2020 amongst 25 countries endorse this assertion with Australia's respondents sharing insignificant negative sentiments of COVID-19 response by their country when compared to others. However, the unweighted sample survey also reveals ambivalent feelings of respondents expressing ratings that shows that the Covid-19 project were either well-done or badly executed. As a result, the indicative fond feelings against dislike for Australia is $74 \%$ fondness in contrast to $20 \%$ dislike. In the same way the respondents were doubtful of their political leaders' flawless response with UK (39\% versus 54\%), Brazil (36\% against $62 \%$ ) and South Africa (59\% as opposed to $41 \%$ ) 
("Cambridge Globalism", 2020). The unprecedented cumulative Covid-19 cases per 1 million population report by WHO on 01 November 2020 globally reached 5,897 with Australia $(1,082)$, UK $(14,902)$, Brazil $(25,953)$, and South Africa $(12,232)$ contributing their relative share (https://www.who.int/). The mortality analysis of death per 100000 population in a country by Johns Hopkins-Coronavirus Resource Center portrays similar trends of fatalities in the four countries. The figures for Australia (3.63), UK (70.60), Brazil (76.50) and South Africa (33.69) as at 4 November 2020 are a probable conjecture about successful or ineffective Covid-19 response by decision-makers of related countries (Johns Hopkins, 2020). Moreover, the global statistics of confirmed Covid-19 cases reported by mid-October suggests a proportional age distribution that slant towards adults (94\%) more than children (6\%) (https://www.who.int/). In turn, IMF reports state that amongst others, Australia, UK, Brazil and South Africa have policy measures of financial relief with beneficial effects to their citizens. That constitute relief to distressed households, low-income workers, and small and medium sized enterprises (SMMEs). Also, central banks of these countries tend to lower their lending rates to commercial banks to encourage lending by distressed companies thus protecting livelihoods against the impact of COVID-19 pandemic (IMF, 2020).

The response of South Africa to the risks and impacts by Covid-19 is given more attention hereafter.

\section{South Africa's Risk Adjusted Strategy on COVID-19}

The government of South Africa has on 15 March 2020 classified the Covid-19 pandemic as a national disaster (https://www.gov.za). Subsequently, the government has invoked the country's Disaster Management Act, 2002 (DMA) with consequent measures of implementing lockdown regulations to address the impact of the COVID-19 situation in the country. The South African Covid-19 regulatory policies are a product of both scientific advice and political decisionmaking by experts and governance structures, respectively. The final regulations produced are a translation of a distinct narrative of a political outlook of government's strategic response to the Covid-19 pandemic. The regulators are informed by a risk management framework to guide the evaluation of Covid-19 spread in the country while attempting to strike a balance between the preservation of social stability and economic solace. South Africa's Risk Adjusted Strategy Framework (RAS) (Figure 2) is an adopted approach to the strategy implementation of Covid19 response and it is used to manage the epistemological uncertainty, ambiguity and complexity discourse of the Covid-19 disease. Therefore, this paper proposes the strategies followed by South African government in mitigating against the imminent catastrophic disease of the Covid19 pandemic.

\subsection{The Formation of the Risk-Adjusted Strategy}

The strategic decision- making process of conceptualizing RAS (Figure 2) is supposed to have adopted a regularizing approach of resolving the Covid-19 problem by comprehension of the analytical methods of Deweys (1910), Simon (1960) and Mintzberg et al. (1976).

Thus, a synopsis of the explication and analysis of the RAS formation is proposed hereafter through three main stages of decision making with each constituting subparts.

\subsubsection{Intelligence (The Identification Phase)}

1. decisions recognition: The South African government department of health reported the first confirmed Covid-19 case on 05 March 2020 supposed to have been imported from Italy upon return of a group of ten travellers into the country. The report assets that authorities have immediately acted upon the impending risk of Covid-19 spread by tracing, isolating and testing the other nine voyagers for the novel coronavirus (https://www.gov.za).

2. the diagnosis course: Already by December 2019 the WHO was informed of the new unknown and enigmatic influenza virus transmissible between human beings in the absence of preventative vaccines and medicines for curing the disease. The precautionary measures 
The Southern Africa Institute of Management Scientists, Independent researcher, South Africa

stated by WHO are mainly social distancing, wearing of face masks, handwashing with water and soap alternatively using alcohol-based hand sanitizer and using a flexed elbow when sneezing or coughing (Rodrigues et al., 2020; https://www.who.int/). Likewise, South African authorities emphasised educational messages of prevention measures to curb uncontrolled spread of Covid-19 infections (https://www.gov.za).

\author{
Prevention \\ * Disaster \\ Management Act \\ *National \\ Command \\ Counsel \\ * Stakeholder \\ profile \\ *Adopted Model \\ Structure
}

$\begin{array}{ll}\text { Preparedness } & \text { Response } \\ \text { * strategic } & \text { *Empirical } \\ \text { procurement \& } & \text { Analysis } \\ \text { stockpiling of } & \text { *Expert } \\ \text { medicines and } & \text { Knowledge and } \\ \text { PPEs } & \text { skill }\end{array}$

Recovery

*Management of

Resource

*Economic Stimulus

Measures

*Social Relief Measures

\section{Strategy Implementation}

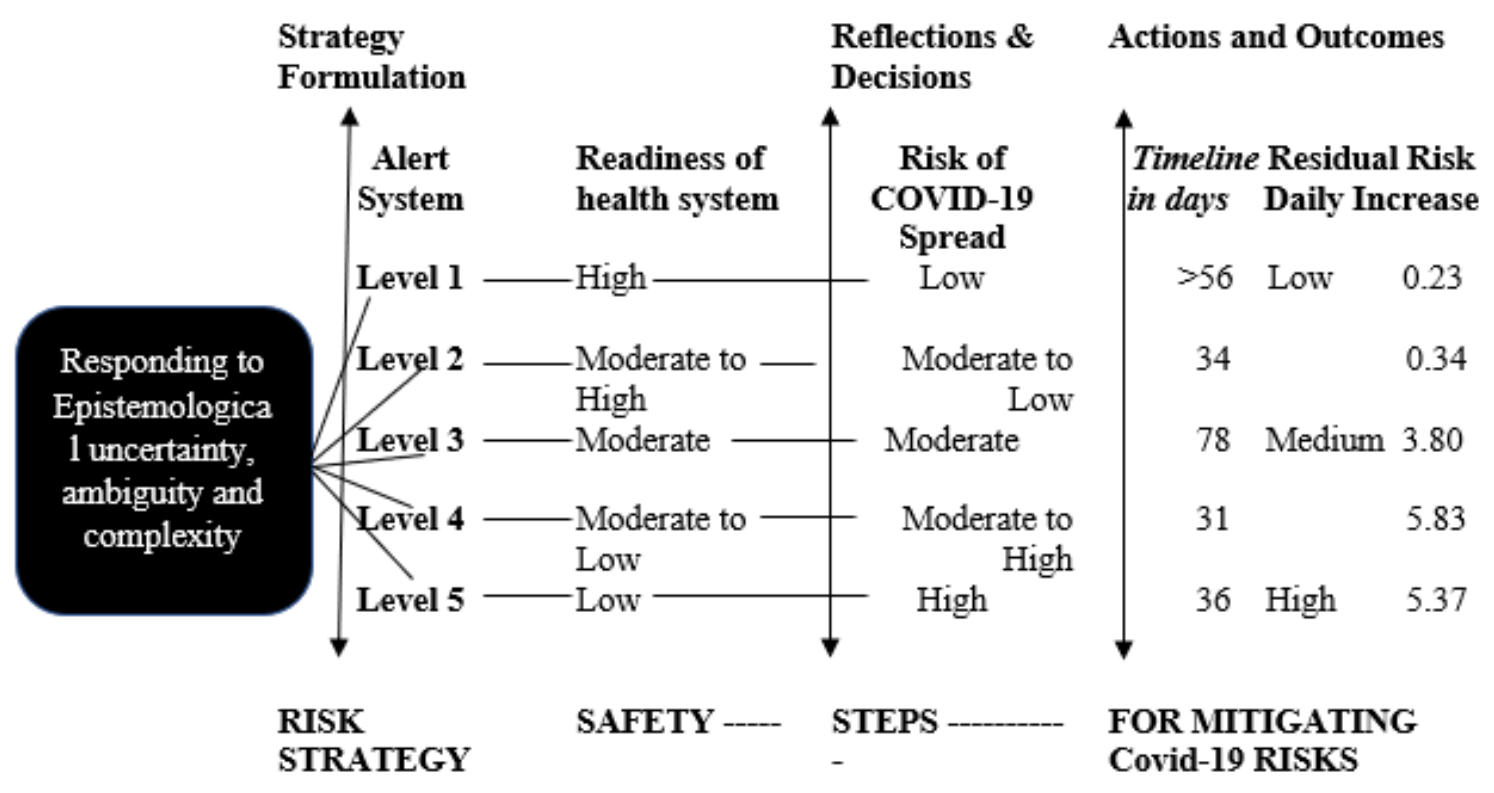

Figure 2: South Africa's Risk Adjusted Strategy Framework on COVID-19

\subsubsection{Design (The Development Phase)}

1. the search: With South Africa facing a looming crisis of a biological disaster and seeking a quick response of contingency plans, in early March 2020 China offered assistance given its managerial experience of attempting to combat the Covid-19 situation (https://www.gov.za). Subsequently, the South-Africa-China cooperation facilitated the offerings of Chinese solutions in fighting the Covid-19 pandemic within South Africa (https://www.gov.za).

2. the design: In order to attain an effective and efficient preventive approach to Covid-19 South Africa as a member country of the UN is bound to seek to follow the guidelines of The Sendai Framework. This guidelines on risk emergency and DRM is in support of the Hugo Framework of action that emphasise shared responsibilities for disaster risk reduction by governments in partnership with stakeholders. It further insists on paying attention to priorities for action that seeks to profile and respond to risk reduction methods of DRM (UNISDR, 2015, p. 9).

\subsubsection{Choice}

1. the selection

a) the screen routine: It is presumed that in a search for a Covid-19 solution South Africa sifted relevant factors from solutions by multilateral cooperation and other international 
communities of alliances before adapting the best options to the RAS framework. The cooperative mechanisms deemed to have included non-state actors also involved the critical roles of experts, particularly health scientists, researchers and modellers.

b) the evaluation-choice, bargaining process and analysis: The scenario planning and analysis as well as stakeholder input and feedback formed a critical role of screening of options towards effective DRM by the RAS approach.

c) judgement: Professional advice which is informed by scientific logic and ingenuity guide the contemplation of strategic policy making decisions on Covid-19 situation by South Africa's government.

2. authorization: South Africa's Cabinet as the executive branch of government serves as a final authority of decision-making and approval of policies under the RAS of the Covid-19 DRM framework ("Covid-19 RAS", 2020).

The various collaborative strategic interventions followed by South Africa are supposed to encompass:

\subsection{Uncertainty Interventions by the Risk-Adjusted Strategy 4.2.1. The Precautionary Principle Approach}

It is suggested that South African authorities have taken precautionary measures, giving rise to the Precautionary Principle, in the face of irreparable loss to happen under scientific uncertainty. In crafting the RAS and its associated regulations South Africa has sought to avoid the consequences of strategic ineptitude and regulatory inaction. The justification of implementing COVID-19 regulatory interventions is necessary since there is, at this time, no firm prognosis of scientific certainty to the situation. Moreover, the Center for Infectious Disease Research and Policy (CIDRAP) of USA predicts that the stretched time horizon of the pervasive Covid-19 pandemic when based on the Spanish Flu model will end in the year 2022. The two years projection is suggested to be conditional to $60 \%$ to $70 \%$ of the world population being relatively unsusceptible to the Covid-19 infection ("The CIDRAP", 2020). Unsurprisingly, South Africa banned sales of tobacco products and smoking during Alert levels 5 to 3 as an attempt to lessen the susceptibility of smokers to Covid-19 virus. The risk analysis experts and scientists with epistemic authority provided information and discernment of the COVID-19 phenomenon. Despite the government's show of scientific logic on the dangers of smoking, the tobacco industry challenged authorities through courts of law fighting against what they deemed as a threat to society's civil liberties. It was incumbent upon the political executive authority to evaluate and decide on the appropriate courses of action which led to the relaxation of tobacco restrictions only post-Alert level 3 (http://www.health.gov.za/). Generally, an accepted notion by Gee and Krayer von Krausss (2005) suggests that public policy making should follow contemplated scientific evidence to avoid the harm of inaction. Still, under an aggressive and pervading COVID-19 pandemic, technocrats were bound to be cautious of early warning systems of a complex-dynamic situation. Thus, some analysts argued that the rational response by policymakers was to put in motion public communication to simplify the understanding of the COVID-19 tobacco risk to society. Notwithstanding, it can be argued that probability models founded in scientific intelligence remain the quintessential tool in determining credible predictions of natural pandemics.

\subsubsection{The Lead Agency Model to Combating Covid-19}

The South African authorities follow a command-and-control management practice to issue authoritative orders which are imbued with a flexible network governance setting. Gorod, Hallo and Nguyen (2018) posit that formal command structures are rigid and ineffective when involving multiple stakeholders in uncertainty situations. Therefore, the inclusion of an adaptable network governance approach seeks to integrate a dual purpose that advances both conformity and adjustability by the National Coronavirus Command Council (NCCC). Too much conformity in addressing the Covid-19 uncertainty and its complex nature may frustrate the need for a more appropriate and practicable response at the face of an imminent disaster. Alternatively, too much flexibility may compromise the mandatory public health measures to combat the spread of Covid-19 pandemic. Still, the imperative Covid-19 response by the NCCC and its subordinate command councils at Provincial level (PCCs) seem logical to permit a complementary coexistence of both command and network structures. Evidently the command and control proposition are designed along a network governance outline which is subdued by an integrative systemic approach. The involvement of key stakeholders, including political parties and both organised business and labour, is said to have aided consensus building by analysis of complexity of an issue through fundamental constituents (https://www.gov.za). All 
the same, the NCCC argued that it relied and resorted to scientific methods of analysing the COVID-19 pandemic by DRM ways. Also, that the preceding COVID-19 regulations in each subsequent Alert level should be judged as a mitigating measure against the grant total of the hazard while also restoring a locality's social standard of quality (Ibid).

In presenting their sectoral regulations, Ministerial clusters resorted to formal reduction strategies of communication to accommodate challenges of interracial communication in society. English remained the primary national language used because of the interracial communication need. However, the evident reality of South Africa's society is that nine official languages- thus the interplay of use of other languages is an unavoidable occurrence to enhance effective crossracial communication amongst communities. It is a compensatory strategy to expand the deficient linguistic understanding by some people by paraphrasing or word coinage (Faerch and Kasper, 1983). Otherwise, the interlanguage strategy of communication is intended to lessen an ambivalent feeling of proficiency in the English language from some in society while also strengthening communication goals and perfecting linguistic insight on COVID-19 to achieve an intended meaning of government interventions. Hence, when making presentations the functional reduction communication strategy included what Faerch and Kasper (1983, 41-44) calls "meaning replacement" and achievement strategy by "interlingual transfer" as a literal transfer English wording to one or more of the native /mother languages.

\subsubsection{COVID-19 Data and Modelling Strategy}

It is proposed that the analysis of COVID-19 requires the opinions of scientists more than those of politicians and pundits who confirms our prejudices. Thus, it is suggested that empirical evidence based on data should sway politicians away from their intransigent political agenda to embrace the scientific judgement as presented. When the outcome of COVID-19 death results is released- the question that remains is as to whether the scientific models had smart predictions or as to whether it was sheer luck. The South African Covid-19 Modelling Consortium (SACMC), established by government, is a primary formation of health scientists, researchers and other experts from academia and the South African National Institute of Communicable Diseases. SACMC updates and reviews the National Covid-19 Epi Model (NCEM) as the main model by the health department of government. NCEM keep to a generalised SusceptibleExposed-Infectious-Recovered (SEIR) structure and is paramount significant in estimating cases of COVID-19 casualties and associated costs by tests and clinical algorithms (https://www.gov.za; https://www.nicd.ac.za/). It is presumed that the primary precursor to the decision-making under the Covid-19 uncertainty event by South Africa's authorities involved strategy techniques by experts using several and different forms of scenario planning. The scientific models showcased in the early stage of the Covid-19 spread were differently developed by epidemiologists, actuarial scientists, health economists and academic researchers. That included The Covid-19 Spatial Model with nondeterministic computation adjusted for local factors like hospital ward level. Van den Heever Model is indifferent to the future prospects of Covid-19 spread but pays attention to changes and adjustments of strategic interventions in chasing the evasive and unpredictable Covid-19 event. As if advancing Van den Heever's model, the Spatial Agent-Based Covid-19 Model (SACOM)'s application is also ward based and inattentive of forecasting the future while curious to predict the effect of varying mitigating measures to be subjected on the Covid-19 uncertainty situation. Also, other Healthcare Covid19 Models are by the Actuarial Society of South Africa (ASSA) and Deloitte. All the scenariobased models provided a predicted South African perspective of the Covid-19 impact albeit from different angles of varying purpose with scanty Covid-19 infection data available during May 2020 (https://www.gov.za).

Initially, the optimistic scenario of a long-term prediction by SACMC suggested that the country would experience 12 million to 13 million symptomatic infections and cumulative 34000 to 50 000 deaths from COVID-19 by early November 2020. The forecasted national death levels are relatively analogous to those forewarned by both Deloitte and ASSA and the long-term and short-term predictions are continually reviewed overtime by SACMC. Also, SACMC's predictions is conditional to the availability of testing data with escalated infections peaking during the JulyAugust 2020 period (https://www.gov.za/; Pulliam et al., 2020). In that, it is supposed that the different scenarios are a precursor to the human resource capacity needs and ancillary tools necessary to the direct relief of Covid-19 disease. However, by 15 November 2020 the actual numbers of COVID-19 confirmed infections was 751024 and fatalities as 20 241(https://sacoronavirus.co.za/). While acknowledging the SACMC defended its antecedent predictions by explaining the exploration of an unexpected hypothesis. Three alternatives are presumed to be important in understanding what gave rise to the startling COVID-19 dynamics. Firstly, authorities should perhaps be credited for a swift response of instituting an aggressive 
lockdown program to rescue the anticipated disaster. Possibly, the resulted outcome from outstanding preparation and great efforts and clear messaging by authorities extricated society from a catastrophic effect. Secondly, since age is deemed as a high-risk factor to soaring numbers of COVID-19 victims, South Africa's youthful population is considered a possible contributory factor to lower cases. Thirdly, the supposed pre-existence of a cross-protective immunity amongst citizens is a plausible explanation of the unrealised COVID-19 prognosis. Particularly, the COVID-19 outbreak transpired against the accepted notion that an intensive wide-spread of COVID-19 is normally experienced in highly crowded areas such as South Africa's informal settlements (Harding, 2020). Still, the hypothetical construct by South Africa's advisory team remain a conjecture though acclaimed to a triumphant risk management approach of a disastrous pandemic.

\subsubsection{COVID-19 Uncertainty and Decision-Making}

It is submitted that the uncertainty phenomenon of COVID-19 poses ambiguous information requiring high-stake strategic decision. South Africa's governing party is accountable to protect the country's citizens from the enigma of the COVID-19 pandemic. Policymaking intervention by the Executives is at first observed by the proclamation of the DMA and its associated regulations which formed a foundation for a governance structure of the COVID-19 event. The subsequent policy decisions of pronouncing amendment of Regulations issued in terms of the DMA is a well-timed end-of-cycle evaluation. It always coincided with a particular forewarning of the next level of spread and intensity of the COVID-19 event expected in the short-term. Hence, the RAS scope of resilience activities are constructed into a thematic development design which incorporate permissions and restrictions at each of the Covid-19 Alert level. Accordingly, in mapping the management of Covid-19 disaster risk reduction by thematic analysis and logical clustering the recognised themes for RAS (https://www.gov.za) include:

Alert Level 1 signalling the lowest state of Covid-19 spread though it is critical for the health system capacity to be at the highest level of readiness.

Alert Level 2 is a hint that although the Covid-19 spread is fairly likely of an average nature the health system still requires laborious preparations to meet the fitness standard for containing the Covid-19 disease.

Alert Level 3 implies a need for a moderate preparedness of the health system to cope with a modest Covid-19 spread while relaxing some restrictions of social activities.

Alert Leve 4 marks a moderate to a high Covid-19 spread demanding a low to moderate health system readiness in proportion to Alert level 5 . The drastic restricting measures of saving lives and tougher curbs on people movements and contacts are still necessary to control the Covid19 outbreak.

Alert Level 5 warning of the existence of a high volume of Covid-19 spread with a likelihood of very serious damages.

Importantly, desperate measures must be taken to suppress the Covid-19 spread and the capacity of the administration of health system should have been already setup, thus a low health system readiness may be sufficient. Evidently, the RAS classification of the Covid-19 Alert levels explains the different allowed adjustment strategies inter-alert levels while emphasising limitations and varying compulsions to restrain the evolution of Covid-19 pandemic within the country. Thus, the five-level Covid-19 system of RAS is a conceptualised classification of Covid-19 Alert levels which distinguish critical elements of the uncertainty of Covid-19. Also, the systematic classification is useful for authorities to pronounce a clear message of their strategic political choices to key stakeholders and the general public. Even though grudgingly declaring a flawed situation of hard lockdown restrictions during March 2020, the different alert level attributes would generally be important decisions pronounced under conditions of inadequate or even lack of sufficient information.

The cyclical nature of amending lockdown regulations started on 01 May 2020, for Alert Level 4 , and followed set periods of evaluation within each thematic analysis. The collected and analysed information throughout the RAS period served as critical response indicators that necessitated executive considerations against planned actions. Noticeably, the early launching of a hard lockdown Alert 5 for 36 days was an attempt by policy makers to satisfy the preparedness in planning for the pandemic. It is suggested that in the midst of continuance of contrasting and interconnected facets of COVID-19 rational foresight with intense exploration 
of information amplified decision making which induced a virtuous circle. Thus, what follows from Alert level 5 is a lowering of strictures imposed on citizens - hence a lockdown downslide from Level 5 to Level 1 over a six months period. However, each reduced level of societal restrictions received opposing opinions. Logically, the scaled down restrictions permitted increased socio-economic activities important for the well-being of the populace. Though, the adverse effect of unrestrained society has a potential to surge the Covid-19 disease rapidly across the country. Still, the execution of the RAS demand that decision-makers should foster for resilient DRM by adjusting regulatory measures to tackle the problematic COVID-19 issue. Also, they should be steadfast in displaying the practice of paradoxical cognition when integrating political and scientific processes that respond to societal needs to contain the pandemic risks. Therefore, the assessment of diverse inputs from different stakeholders calls for balancing of opposing views and reframing propositions into clear objectives when developing or revising COVID-19 rules. To transcend logic into rules will also demand the shifting of paradox mindset boundaries and reveal the values of polarities likely to advance the RAS goals. It is proposed that over time decision-makers while embracing contrasting views they engaged steadily in expansive learning of the pandemic. Expectedly, the thoughtful and reflective thinking choice of strategic alternative decisions generated progressive rules with a positive social change.

The applications of risk strategies associated to the RAS by the NCCC with the subsequent regulatory changes of permissions and restrictions on the Covid-19 situation is deemed to have led to residual risks of the Covid-19 event. The average relative daily increase of Covid-19 in South Africa is supposed to be indicative of the effectiveness of mitigation measures by the NCCC. Prior to the inception of lockdown measures South Africa was experiencing the average relative daily increase of 40.74 cases. Noticeably, Figure 2 shows that Covid-19 cases abated post implementation of lockdown restrictions from 26 March 2020 with Covid-19 high residual risk of spread at Alert Level 5 being averagely 5.37 daily and sliding down to an eventual low risk score of 0.23 in Level 1 mid-November 2020. Thus, policy-makers seem to have succeeded in coercing the adaptation of societal behaviour while having accepted the residual risks at each Alert level as they continue to reduce future restrictions over the Covid-19 event. However, the stretched 78 days of Alert level 3 suggests that the NCCC postponed or delayed the Covid-19 regulatory reviews due to an ambivalent attitude to suitable strategic interventions and unexpected consequences of the Covid-19 situation.

\subsubsection{The Paradox of Covid-19 Expenditure Against the National Development Strategy}

As a result of the COVID-19 expenditure, pressure is placed on the fiscus of South Africa. In turn, the government has resorted to increase its sovereign debt over GDP by large amounts of foreign currency-denominated debt. The intended borrowing is targeted for sourcing from multilateral finance institutions (US\$7 billion), New Development Bank of the BRICS countries (US\$1 billion) and from the IMF (US\$4.2 billion)'s low-interest emergency facility. As a result, the gross national debt has escalated from $65.6 \%$ of the budget estimate of $2020 / 21$ to $81.8 \%$ post the gross borrowing effect. The government debt to nominal GDP ratio of $69.4 \%$ in June 2020 has since increased sovereign risk of indebtedness threatening the country's safe borrowing levels in the future (http://www.treasury.gov.za/). Regrettably, by March 2020 the main three credit rating agencies, Moody's, Standard \& Poor and Fitch, had already downgraded South Africa to sub-investment grade. The junk status presents a negative outlook that threatens the country's economic growth. The structural fundamentals of weak economic growth, fiscal strength and ineffective policies need to be given urgent attention especially since the economy is projected to contract by $7.2 \%$ in 2020 (http://www.treasury.gov.za/). Therefore, in order to bridge the public finance distress gap and regain socio-economic position of prior Covid-19, South Africa's three-phased response is targeted at:

Phase 1: preservation of the economy by immediate and interim measures. The South African government has taken a pre-emptive action against further negative effects of Covid-19 through provision of a fiscal package of about R500 billion (US\$30 billion) (http://www.treasury.gov.za/). Hence, the country's short-term stimulus for Covid-19 losses are directed, amongst others, to the provision of relief financing to the unemployed and distressed businesses. The temporary payments for Unemployment Insurance Fund (UIF TERS) is supposed to be a low-income targeting strategy, with the aim of extending government social expenditure to those who are low income earners and have decreased income due to the brand of COVID-19. The flat rate special social grant to the unemployed serving as a short-term social security benefit is deemed as an egalitarian strategy purposed to offer a social compensation to victims of the COVID-19 pandemic (IMF, 2020). 
Phase 2: the planned recovery from dire consequences of the Covid-19 effects. The economic pressures by COVID-19 is deepening the country's economic downturn and rapidly imposing socio-economic reversals against the intent of the National Development Plan 2030 (NDP). South Africa's NDP is a national strategy intended to reduce poverty and lessen inequality while growing the country's economy by 2030 . The country's recovery plan from the pandemic seem to resemble intentions of the NDP, particularly in the primary objectives of fulfilling a positive social purpose while advancing economic ambitions (https://www.gov.za/). However, the NDP's prime aim of ensuring efficiency in government seem to have been thrown into a state of flux. The Covid-19 uncertainty with its urgent capacity utilization requirements is deemed to have distorted the NDP growth path. In the meantime, a new direction of socio-economic progression is dictated by an increased demand of quality healthcare necessities at the expense of other essential elements of the NDP.

Phase 3: repositioning the economy to accelerate growth while restoring longstanding and stable societal well-being. South Africa's desperate economic situation is worsened by high unemployment percentage of the total labour force $(28.5 \%)$ that is unfavourably compared to its BRICs partners like Brazil (12.0\%), most of the G20 countries such as Australia (5.3\%), and of the G8 countries like UK ( $4.1 \%$ ) (see Table 1 ). Hence, the low-capacity utilization resulting from lockdown periods and deepened high unemployment level has become problematic for fiscal policy and SARB as a monetary policymaker. By October 2020 the South African Reserve Bank (SARB) was compelled to cut the repo rate interest rates by 275 -basis point to control inflation in comparison to the median cut of 100-basis effected by emerging markets. Consequently, commercial banks provided 90 -day payment holidays as relief to financially distressed clients, including interest-free loans and grants to SMMEs (http://www.treasury.gov.za/). Importantly, South Africa need to stimulate its aggregate demand for goods and services as a reprieve from Covid-19 situation.

\section{Conclusion}

The Covid-19 risk management framework of South Africa is a typical exhibition of a disaster risk strategy in severe uncertainty. The identified approaches referenced under the Covid-19 situation of South Africa have exposed influencing risk management factors. Also, the response to ambiguities have unveiled an understanding of the uncertainty and its associated influences. In tailoring its strategy of counteracting the Covid-19 situation, South Africa applied strategic decisions presumed to have partly addressed the paradoxical effects of the pandemic. Nevertheless, South Africa's risk adjusted strategy against the Covid-19 event is deemed to be no exception from the experience of countries worldwide. Still, the uncertainty, ambiguity and complexity discourse will continue to occupy researches and practitioners that are interest in disaster risk management. This paper gives insight on the effects of uncertainty within the context of strategic interventions by public officials.

\section{Acknowledgement}

This study was personally funded by the researcher. The data used in the analysis was mainly taken from referenced publications. The statements made herein are solely the responsibility of the author.

\section{References}

- Agencies and Sum, M. (2020 November 2). Mixed feelings as UK heads into lockdown. The Standard newspaper. Available at: https://www.thestandard.com.hk/sectionnews/section/11/224330/Mixed-feelings-as-UK-heads-into-lockdown. (Accessed: 10 November 2020).

- Anderson, P. 1999. Complexity Theory and Organization Science. Organization Science.10(3), 216 -232. CrossRef

- Australian Government. Department of Health. (2018). Emergency Response Plan for Communicable Disease Incidents of National Significance: National Arrangements (National $C D$ Plan). Australia. Available at: https://www1.health.gov.au/internet/main/publishing.nsf/Content/ohp-nat-CD-plan.htm. (Accessed 06 November 2020). 


\section{Jeremiah Kau Makokoane}

The Southern Africa Institute of Management Scientists, Independent researcher, South Africa

- Australian Government. (2020). 3-Step Framework for a CovidSafe Australia. Australian Government. Australia. Available at: https://www.health.gov.au/resources/publications/3step-framework-for-a-covidsafe-australia. (Accessed: 06 November 2020).

- Bekkers, V., and Thaens, M. 2005. Interconnected networks and the governance of risk and trust. Information Polity: The International journal of Government \& Democracy. $10(1,2)$, 37-48. CrossRef

- Burnes, B. 2005. Complexity theories and organisational change. In International Journal of Management Reviews. 7 (2), 73-90. CrossRef

- Byrne, D. (1998) Complexity Theory and the Social Sciences. An Introduction. London and New York: Routledge.

- Chintakananda1, A., McIntyre, D.P., and Chen, E.W. 2015. Uncertainty in Strategic Management Research: Three Unresolved Tensions. Strategic Management Review, 9(1), 55- 75.

- COVID-19 Risk Adjusted Strategy (Covid-19 RAS). (2020) - SA Corona Virus Online. Available at: https://sacoronavirus.co.za/covid-19-risk-adjusted-strategy/. Accessed: 20 October 2020).

- Dequech, D. 2011. Uncertainty: A Typology and Refinements of Existing Concepts. Journal of Economic Issues. 3, 621 - 640. CrossRef

- Dooley, K.J. 1997. A Complex Adaptive Systems Model of Organization Change. Nonlinear Dynamics Psychology and Life Sciences 1(1):69-97. CrossRef

- Funtowicz, S. and Ravetz, J. (1990). Uncertainty and Quality in Science for Policy. Kluwer, Amsterdam $\underline{\text { CrossRef }}$

- Gorod, A., Hallo, L. \& Nguyen, T. 2018. A Systemic Approach to Complex Project Management: Integration of Command and-Control and Network Governance. Systems Research and Behavioral Science 35(4). CrossRef

- Gee, D. and Krayer von Krauss. 2005. Late Lessons from early warnings: towards precaution and realism in research and policy. Water Science and Technology. 52(6), 25-34. CrossRef

- Gurkov, I. 2010. Strategy techniques for the times of high uncertainty. Journal for East European Management Studies · January 2010. CrossRef

- Harding, A. (2020, September 2). Coronavirus in South Africa: Scientists explore surprise theory for low death rate. BBC News Africa. Available at: https://www.bbc.com/news/worldafrica-53998374. Accessed: 18 October 2020).

- IMF. (2020). Policy Responses to Covid-19. Policy Tracker. International Monetary Fund. Available at: https://www.imf.org/en/Topics/imf-and-covid19/Policy-Responses-to-COVID19. (Accessed: 05 November 2020).

- Johns Hopkins University of Medicine. (2020). Coronavirus Resource Center, Available from: https://coronavirus.jhu.edu/data/mortality. (Accessed: 4 November, 2020)

- Kreye, M.E., Newnes, L.B. and Goh, Y.M. Uncertainty Alanysis and its Application to Service Contracts. (August 28 - 31, 2011). Proceedings of the ASME 2011 International Design Engineering Technical Conferences \& Computers and Information in Engineering Conference. IDETC/CIE. Washington, DC, USA. CrossRef

- Lindgren, M and Bandhold,H. (2003). Scenario Planning The link between future and strategy. Palgrave MacMillan. New York. CrossRef

- Mileti, D. (1999). Disasters by Design. A Reassessment of Natural Hazards in the United States. Joseph Henry Press. Washington, D.C. USA.

- Mintzberg, H., Raisinghani, D. and Théorêt, A. 1976. The Structure of 'Unstructured' Decision Processes. Administrative Sciences. Quarterly (21), 246-275. CrossRef

- Nojavan, M., Salehi, E. \& Omidvar, B., 2018, 'Conceptual change of disaster management models: A thematic analysis', Jàmbá: Journal of Disaster Risk Studies 10(1), a451. CrossRef

- Patrick, O. (2020, October 1 ). The secret to Australia's success in beating the coronavirus? Being an island helps. Washington Post Newspaper. Available from: https://www.washingtonpost.com/world/asia pacific/coronavirus-australia-bordersquarantine/2020/10/01/29e53608-0223-11eb-b92e-029676f9ebec story.html. (Accessed: 15 October 2020). 
The Southern Africa Institute of Management Scientists, Independent researcher, South Africa

- Pulliam,J., Silal, S., Meyer-Rath, G. and Moultrie, H. (2020, May 22). Behind the numbers: Modelling the spread of Covid-19 in South Africa. News24. Available at: https://www.news24.com/news24/Analysis/analysis-behind-the-numbers-modelling-thespread-of-covid-19-in-south-africa-20200521. (Accessed: 22 September 2020).

- Quarantelli, E.S. 1998. Major Criteria for Judging Disaster Planning and Managing their applicability in Developing Countries. University of Delaware: Disaster Research Center. Available at: http://udspace.udel.edu/handle/19716/286. (Accessed: 10 August 2020)

- Ramalingam, B., Wild, L. and Ferrari, M. 2020. Adaptive leadership in the coronavirus response: Bridging science, policy and practice. Overseas Development Institute (ODI). Available from: https://www.odi.org/publications/16817-adaptive-leadership-coronavirusresponse-bridging-science-policy-and-practice. (Accessed: 20 August 2020).

- Redmond, M.V. 2015. Uncertainty Reduction Theory. English Technical Reports and White Papers. Available from: http://lib.dr.iastate.edu/engl_reports/3. Accessed: 18 August 2020).

- Rodrigues, K.F., Carpes, M.M. and Raffagnato,C.G. 2020. Disaster preparedness and response in Brazil in the face of the COVID-19 pandemic. Revista de Administração Pública.54(4). CrossRef

- Phillips. T. (2020, August 9). We failed': one scientist's despair as Brazil Covid-19 deaths hit 100,000. The Guardian-Latin America. Available from: https://www.theguardian.com/world/2020/aug/09/brazil-covid-19-deaths-nataliapasternak-bolsonaro. (Accessed: 05 September 2020).

- Simonovic, S.P. 2015. Systems Approach to Management of Disasters - A Missed Opportunity? Journal of Integrated Disaster Risk Management. 5(2), 70- 83. CrossRef

- The World Bank. (2019). Population Total, All Countries and Economies. Available from. https://data.worldbank.org/indicator/SP.POP.TOTL. (Accessed: 05 October 2020).

- The World Bank. (2020). Unemployment, total (\% of total labour fource). Available from; https://data.worldbank.org/indicator/SL.UEM.TOTL.ZS. (Accessed: 05 October 2020).

- Thomson, J., Hetzler, B., MacEachren, A., Gahegan, M. and Pavel, M. (2005). A Typology for Visualizing Uncertainty. 16-20. CrossRef

- Tosey, P., Visser, M., and Saunders, M. 2012. The origins and conceptualizations of 'tripleloop' learning: A critical review. Management Learning.43, 291. CrossRef

- United Kingdom government (UK). (2020). Coronavirus: action plan. A guide to what you can expect across the UK. Emergency and Health Protection Directorate. Crown copyright 2020. Available from: www.gov.uk/dhsc. (Accessed: 24 October 2020).

- University of Minnesota. 2020. COVID-19: The CIDRAP Viewpoint. Part 1: "The future of the COVID-19 pandemic: lessons learned from pandemic influenza". Available from: https://www.cidrap.umn.edu/sites/default/files/public/downloads/cidrap-covid19viewpoint-part1 0.pdf. (Accessed: 30 April 2020).

- United Nations Office for Disaster Risk Reduction (UNISDR). 2015. Sendai Frameworkfor Disaster Risk Reduction 2015 - 2030. United Nations. Geneva, Switzerland. Available from: https://www.undrr.org/publication/sendai-framework-disaster-risk-reduction-2015-2030. (Accessed: 05 August 2020).

- Van de Kuilen, G. and Wakker, P.P. 2006. Learning in the Allais paradox. J Risk Uncertainty. 33, 155-164. CrossRef

- Walker, W.E., Harrem€oes, p. Rotmans, J., van der Sluijs, J.P., van Asselt, M.B.A., Janssen, P. and von Krauss, M.P. 2003. Defining Uncertainty: A Conceptual Basis for Uncertainty Management in Model-Based Decision Support. Integrated Assessment, 4 (1), 5-17. CrossRef

- WorldAware. (2020, April 30). Covid-19 Alert: Brazil Extends Travel Restrictions Until Late May, Regional Movement Restrictions Through Mid May. WorldAware Company. Available from: $\quad$ https://br.usembassy.gov/health-alert-extension-of-brazil-travel-restrictions-onland-and-sea-borders-3/. (Accessed: 25 August 2020).

- YouGov. (30 July - 24 August 2020). YouGov Cambridge Globalism 2020 Fieldwork. YourGov. Available from: https://yougov.co.uk/topics/international/survey-results.(Accessed: 11 November 2020) 


\section{Appendix}

\section{Professional Biography}

Dr. Jeremiah Makokoane's research interests are in the areas of organisational productivity, leadership and organisational development with particular focus on the South African public sector institutions. He holds a Doctorate degree in Applied Management from Monarch Business School in Switzerland, a Master's degree in Business Administration (MBA) from the Management College of Southern Africa, and a Bachelor's degree in Commerce from the University of South Africa (UNISA). Dr. Makokoane has over 20-years' experience as a public servant. He is currently a member of The Southern Africa Institute of Management Scientists and writes as an independent researcher. 